Rev. Elet. em Gestão, Educação e Tecnologia Ambiental (e-ISSN: 2236-1170)

\title{
GESTÃO DOS RESÍDUOS SÓLIDOS URBANOS: A VISÃO DA POPULAÇÃO NA CIDADE DE FREDERICO WESTPHALEN
}

\section{MUNICIPAL SOLID WASTE MANAGEMENT: THE VISION OF POPULATION IN THE CITY OF FREDERICO WESTPHALEN}

\author{
Pedro Daniel da Cunha Kemerich', Alexandre Couto Rodrigues ${ }^{2}$, Fernado Ernesto Ucker ${ }^{3}$, Vanessa \\ Deisi Renz ${ }^{4}$, Aline Haas ${ }^{5}$
}

\footnotetext{
${ }^{1}$ Graduação em Engenharia Ambiental pelo Centro Universitário Franciscano -UNIFRA (2005),Mestrado pela Universidade Federal de Santa Maria - UFSM, em Recursos Hídricos e Saneamento Ambiental (2008), Pós-Graduação em Engenharia de Segurança do Trabalho pelo Centro Universitário Franciscano - UNIFRA (2009),Doutorando do Programa de Pós-Graduação em Engenharia Ambiental da Universidade Federal de Santa Catarina.Coordenador do Curso de Engenharia Ambiental da Universidade Federal de Santa Maria/CESNORS.

.2 Graduação em Engenharia Agronômica (1992), Mestrado em Ciências (1996), Doutorado em Ciências, pela Universidade Federal de Pelotas (2000) e Pós-Doutorado em Ecofisiologia Vegetal pelo Institut National de la Recherche Agronomique INRA - França (2001). Professor Adjunto da Universidade Federal de Santa Maria.

${ }^{3}$ Graduação em Engenharia Ambiental pelo Centro Universitário Franciscano - UNIFRA (2009), Mestrado em Engenharia do Meio Ambiente pela Universidade Federal de Goiás - GO.

${ }^{4}$ Acadêmica do Curso de Engenharia Ambiental - UFSM/CESNORS

${ }^{5}$ Acadêmica do Curso de Engenharia Ambiental - UFSM/CESNORS
}

http://dx.doi.org/10.5902/223611707436

\section{RESUMO}

O envolvimento da sociedade nas questões ambientais é de extrema necessidade, onde cada indivíduo se torna responsável pela produção e destinação de seus resíduos, assim se cria uma articulação entre cidadania e educação ambiental. Os resíduos domésticos fazem parte do vilão que vincula a destruição do ambiente e o esgotamento dos recursos naturais, além de inúmeros problemas relacionados. O presente trabalho teve como objetivo identificar as formas de descarte, conhecimento sobre resíduos domésticos, métodos de separação e destinação destes materiais, utilizados pela população da cidade de Frederico Westphalen - RS, bem como danos causados ao ambiente e formas corretas de diminuir esses impactos com novos métodos de consumos consciente. $\mathrm{O}$ trabalho demonstrou que quanto maior o nível de instrução do indivíduo, maior a sua conscientização ambiental.

Palavras-chave: resíduo doméstico, meio ambiente, destinação.

\begin{abstract}
The society involvement in environmental issues is of extreme necessity, where each individual is responsible for the production and disposal of their waste, thus establishing a link between citizenship and environmental education. Household waste are part of the villain that links the destruction of the environment and depletion of natural resources, in addition to numerous problems. This study aimed to identify ways to dispose of, knowledge about household waste separation methods and disposal of these materials, used by the population of the city of Frederico Westphalen - RS, as well as environmental damage and correct ways to reduce these
\end{abstract}


impacts with new methods of conscious consumption. The study demonstrated that the higher the education level of the individual, the greater its environmental awareness.

Keywords: household waste; environment; allocation.

\section{INTRODUÇÃO}

O homem, desde o início da civilização, buscou acumular riquezas utilizando recursos naturais á sua volta. Quando esses rareavam, empreendia luta na tentativa de encontrar mais e melhores recursos em outras regiões, assegurando as condições de sobrevivência de seu grupo, submetendo povos e seus recursos naturais à sua ganância e exploração.

A produção de resíduos faz parte do cotidiano do ser humano. Devido ao crescente aumento da população que geralmente ocorrem com maior intensidade em centros urbanos ocasionam mudanças nas formas de ocupação desses espaços e o ritmo de consumo cada vez mais acelerado, propiciando problemas relacionados a esses resíduos que se tornam mais visíveis.

Os resíduos constituem uma preocupação ambiental mundial, especialmente em centros urbanos. Os resíduos, quando coletados e tratados inadequadamente, provocam efeitos diretos e indiretos na saúde da população e contribuem para degradação do ambiente (GRANZIERA, 2009).

Os resíduos são matérias e substâncias que, depois de utilizados, se não tiverem uma destinação final ambientalmente adequada podem por em risco as atividades que venham a ser desenvolvidas onde foram dispensados (GRANZIERA, 2009).

Segundo o Conselho Nacional do Meio Ambiente (CONAMA) em sua resolução n. $5 / 93$, artigo $1^{\circ}, \mathrm{I}$, os resíduos podem resultar de atividades da comunidade de origem industrial, doméstica, hospitalar, comercial, agrícola, de serviços e de variação. Em relação aos resíduos domésticos, Ribeiro (2006) afirma que os principais componentes são restos alimentares, papel, vidro, pano, madeira, metal, osso e material ocioso (terra, por exemplo), gerados pelas atividades cotidianas dos lares.

O lixo mal acondicionado significa poluição ambiental e risco à segurança da população. No Brasil a geração de Resíduos Sólidos Urbanos em 2009 se intensificou, com uma produção de aproximadamente 57 milhões de toneladas, equivalendo a um crescimento de $7,7 \%$ em relação ao ano de 2008, que teve uma produção anual próxima dos 53 milhões de toneladas (ABRELPE, 2009).

Para Pimenta et al. (2006) a separação do lixo é uma prática de ótica coletiva, além de individual, porque visa à preservação da qualidade do ambiente em seu coletivo. Assim, colocar o lixo no local adequado e participar de movimentos a favor do cuidado com o meio ambiente são ações individuais que tem efeito social. Este é um problema de saúde pública, que envolve questões de interesse coletivo, mas profundamente influenciado por interesses econômicos e por manifestações da sociedade, por aspectos culturais e por conflitos políticos.

Com base no exposto acima, o presente trabalho teve como objetivo verificar o grau de sensibilização da população de Frederico Westphalen - RS sobre a necessidade de realizar o descarte correto dos resíduos domésticos, sua separação e possível reciclagem, bem como verificar o conhecimento dos mesmos sobre os possíveis danos ao meio ambiente em conseqüência da disposição incorreta deste material. 


\section{METOdOLOGIA}

Para a realização do presente trabalho, foi elaborado um questionário contendo vinte perguntas, sendo quinze objetivas e cinco dissertativas, referentes ao conhecimento e aos hábitos dos moradores de Frederico Westphalen - RS, quanto à disposição, descarte e a problemática ambiental causada pelo resíduos domésticos.

Buscou-se aplicar o questionário no comércio, nas empresas, para pedestres e moradores em geral do município. Foram abordadas pessoas de todas as idades e classes sociais, totalizando 100 pessoas em um universo amostral de 28.843 habitantes, ou seja, 0,347\% da população local (IBGE, 2012). Dentre os itens abordados estão: o conhecimento sobre o descarte correto a ser dado ao resíduo doméstico, sua separação e possível reciclagem, os impactos ambientais, os riscos a saúde ocasionados pela destinação incorreta desses materiais e métodos de consumo consciente.

No questionário aplicado, investigou-se uma série de elementos, os quais estão elencados no quadro 1. Após a aplicação do questionário, as respostas foram analisadas e representadas em forma de gráficos para melhor visualização e discussão.

Quadro 1. o questionário aplicado à população de Frederico Westphalen.

\begin{tabular}{|c|}
\hline 1. Nível de Escolaridade. \\
\hline 2. Renda Familiar. \\
\hline 3. Conhecimento à cerca dos Resíduos Domésticos. \\
\hline 4. Conhecimento à cerca da separação destes resíduos. \\
\hline $\begin{array}{l}\text { 5. Nível de satisfação referente à separação dos resíduos na cidade de Frederico } \\
\text { Westphalen. }\end{array}$ \\
\hline 6. Conhecimento referente ao termo "Coleta Seletiva". \\
\hline 7. Presença ou ausência deste tipo de coleta. \\
\hline $\begin{array}{l}\text { 8. Quanto à realização da compostagem como método de separação do } \\
\text { resíduo. }\end{array}$ \\
\hline 9. Diferenciação de aterros sanitários e lixões. \\
\hline 10. Problemática relacionada aos aterros. \\
\hline 11. Quanto a presença de componentes tóxicos nos resíduos domésticos. \\
\hline 12. Quanto à disposição de materiais potencialmente tóxicos em aterros. \\
\hline 13. Quanto aos problemas acarretados com a disposição inadequada. \\
\hline 14. Possível opinião sobre formas corretas de separação e destino. \\
\hline 15. Medidas ambientalmente corretas. \\
\hline 16. Possível motivação com métodos de consumo consciente. \\
\hline $\begin{array}{l}\text { 17. Quanto à realização de divulgação em mídia, campanhas e palestras } \\
\text { referentes aos Resíduos Sólidos Urbanos na cidade de Frederico Westphalen. }\end{array}$ \\
\hline
\end{tabular}


Rev. Elet. em Gestão, Educação e Tecnologia Ambiental (e-ISSN: 2236-1170)

\section{RESULTADOS E DISCUSSÃO}

A pesquisa foi realizada nos bairros do município, obtendo-se os seguintes resultados: dos entrevistados, $5 \%$ residem no bairro Santo Antônio, $26 \%$ residem no Centro, $5 \%$ residem no bairro Barril, $12 \%$ residem no bairro Itapajé, $7 \%$ residem no bairro Santo Inácio, 3\% residem na Linha Auto Alegre, $6 \%$ residem no bairro Primavera, $14 \%$ residem no bairro Ipiranga, $12 \%$ residem no bairro Fátima, 7\% residem no bairro Aparecida e 3\% residem nos bairros 21 de abril, Vila Branca e Linha Locateli.

Com a aplicação do questionário, constatou-se que $60 \%$ das pessoas interrogadas tinham idade média entre 25 a 35 anos.

Os resíduos domésticos gerados no município têm origem da vida diária das residências, constituído por restos de alimentos, (cascas de frutas, verduras), papel (jornais, revistas), embalagens em geral (vidro, papelão, alumínio), resíduos contaminados como papel higiênico, fraldas descartáveis e resíduos tóxicos (tintas, esmaltes, aerossóis).

Segundo a Associação Brasileira de Empresas de Limpeza Pública e Resíduos Especiais (Abrelpe, 2011) a composição gravimétrica dos Resíduos Sólidos Urbanos no Brasil de um modo geral diversifica-se na presença de $51,4 \%$ de matéria orgânica, 31,9\% de materiais recicláveis e $16,7 \%$ de outros tipos de materiais. Porém a destinação dos mesmos ainda permeia em 41,94\% inadequada, como mostrou pesquisas realizadas pelo Plano Nacional de Resíduos Sólidos de 2012.

De modo geral, esses resíduos quando manuseados e dispostos de forma inadequada no meio ambiente podem ocasionar problemas sanitários, como também, deteriorando a paisagem e desperdiçando oportunidades de obtenção de renda.

A média de geração de resíduos sólidos urbanos no país, segundo projeções do Sistema Nacional de Informações sobre Saneamento - SNIS (2010) da Associação Brasileira de Empresas de Limpeza Pública e Resíduos Especiais - Abrelpe (2011), varia de 1 a 1,15 kg por hab./dia.

Em relação ao nível de escolaridade da população entrevistada, obteve-se: $51 \%$ possuíam algum tipo de instrução, ensino fundamental, médio ou ensino superior, porém incompleto e $49 \%$ possuíam instrução, ensino fundamental, médio ou ensino superior completo (Figura 1).

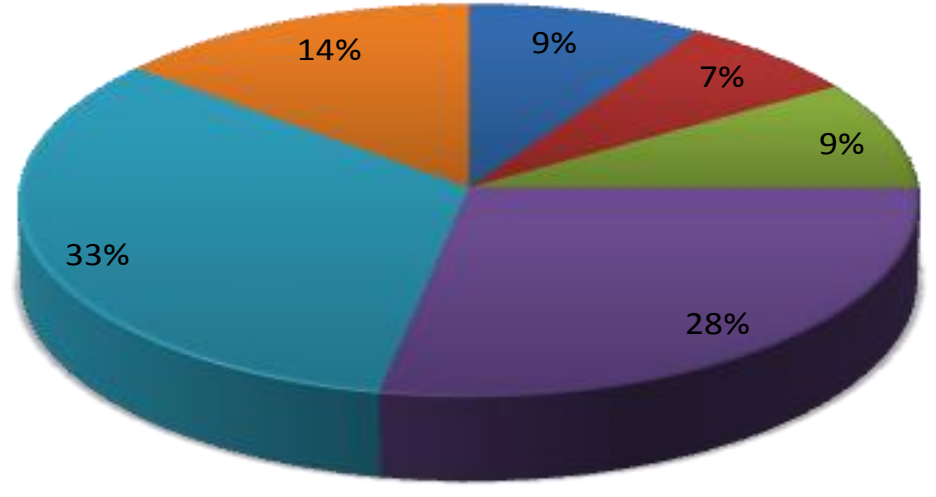

Figura 1. Nível de Escolaridade da população entrevistada.
Ensino Fundan Incompleto

- Ensino Fundan Completo

Ensino Médio Incompleto

- Ensino Médio Completo

$\square$ Ensino Superic Incompleto

$\square$ Ensino Superic Comnleto

Com relação à renda familiar, $1 \%$ das pessoas declararam ter renda familiar menor que um salário mínimo, $9 \%$ das pessoas declararam possuir entre 1.1 a 1,9 salários, $49 \%$ possuíam renda 
entre 2,0 a 4,9 salários mínimos, 25\% possuíam renda superior a 5 salários mínimos e 16\% preferiram não relatar, como pode ser observado na Figura 2.
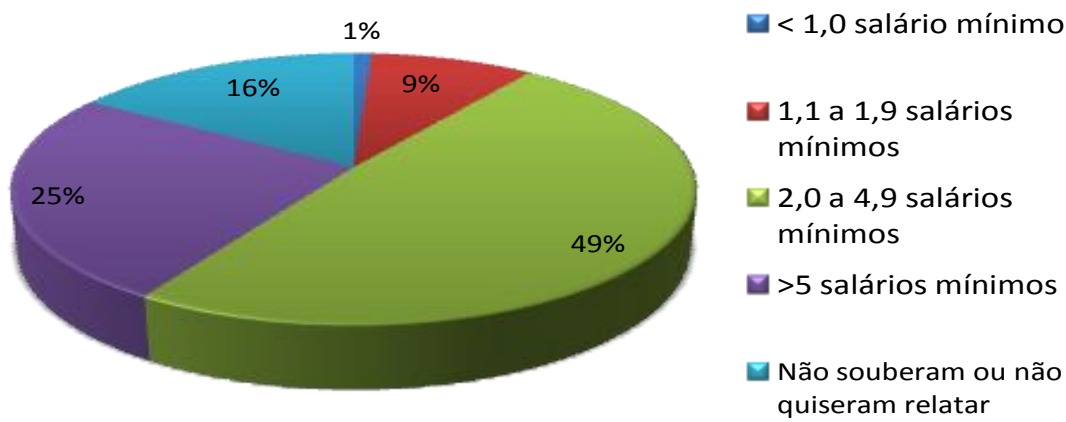

Figura 2. Renda Familiar dos entrevistados.

Quando perguntados sobre o seu conhecimento referente aos resíduos domésticos, 95\% das pessoas afirmaram possuí-lo, e os $5 \%$ restantes, alegaram não possuir.

Para a separação dos resíduos domésticos nas residências, $57 \%$ dos entrevistados afirmaram realizar a separação, e os $43 \%$ restantes não realizam nenhum tipo de separação. Podese observar que $99 \%$ dos entrevistados que realizam a separação á fazem em orgânico e inorgânico.

Referente à separação do lixo do município $29 \%$ da população entrevistada está satisfeita com a separação do lixo, $51 \%$ estão insatisfeitos, $14 \%$ consideram o modelo de separação péssimo e 6 \% não sabem ou não tem conhecimento sobre o assunto, conforme figura 3.

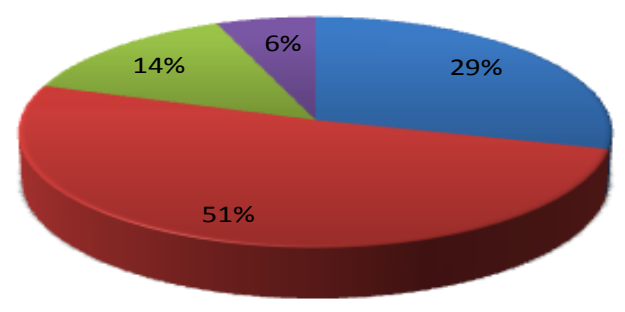

\author{
Satisfatório \\ घ Insatisfatório \\ Péssimo \\ Não souberam ou \\ não quiseram \\ relatar
}

Figura 3. Gráfico da separação dos resíduos no município.

No que se refere aos resíduos domésticos, à coleta seletiva é o primeiro estágio para a reciclagem. A Figura 4 demonstra que $83 \%$ dos entrevistados afirmam saber o que é coleta seletiva, $13 \%$ não possuem este conhecimento e $4 \%$ apresentaram dúvida. 


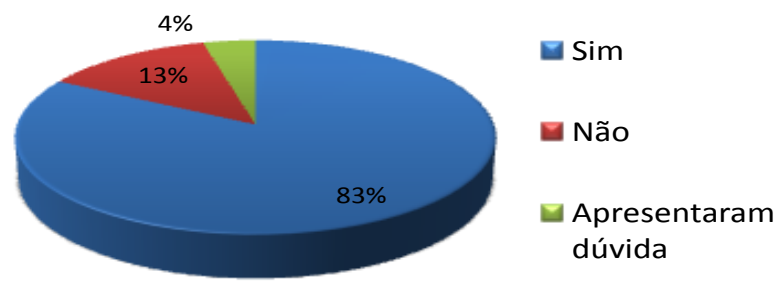

Figura 4. Gráfico referente ao conhecimento sobre a realização da coleta seletiva.

Questionados sobre o sistema de coleta de resíduos domésticos do município, $58 \%$ da população entrevistada afirmou que não existe sistema de coleta, 37\% afirmam que sim, que o município possui algum sistema de coleta e $5 \%$ não souberam relatar, conforme mostrado na Figura 5.

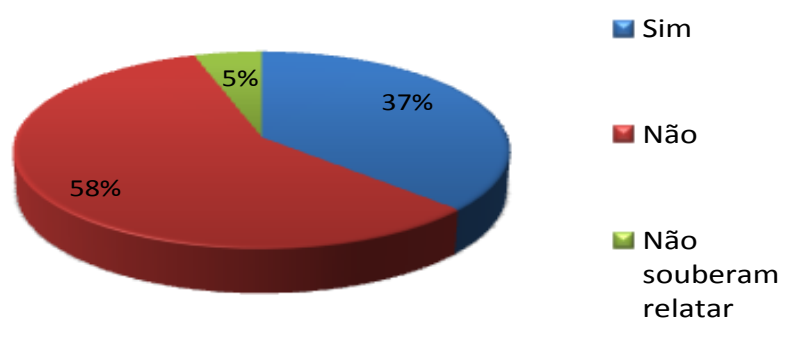

Figura 5. Gráfico a respeito do conhecimento da existência de sistema de coleta de resíduos.

Sobre a compostagem, Reis, Fadigas e Carvalho (2012) afirmam que este processo consiste na decomposição de matéria orgânica de origem animal ou vegetal em processos biológicos, tendo como resultado final o composto orgânico. O questionário apontou que $29 \%$ das pessoas realizam a compostagem e outras $71 \%$ não.

O método mais adequado posteriormente a reciclagem seria o descarte em aterros sanitários, onde o material é disposto sem causar danos ou riscos à saúde pública e à segurança, minimizando os impactos ambientais. Método que utiliza princípios de engenharia para confinar resíduos sólidos à menor área possível e reduzi-los ao menor volume possível, cobrindo-os com uma camada de terra na conclusão da jornada de trabalho ou a intervalos menores, se necessário (IPT, 1995).

A responsabilidade do tratamento do lixo dependerá da estrutura do município em que foi produzido. Legalmente, as prefeituras são responsáveis pela coleta, transporte e disposição do lixo domiciliar, comercial e dos espaços públicos. As alternativas de descarte destes materiais são: reciclagem, reutilização, compostagem, incineração, aterro sanitário ou depósitos de lixo. Os lixões não são uma alternativa responsável, embora seja o mais comum entre os municípios brasileiros. 
Rev. Elet. em Gestão, Educação e Tecnologia Ambiental (e-ISSN: 2236-1170)

Quando questionados sobre a diferença entre lixões e aterros sanitários, 57\% da população entrevistada afirmaram saber quais são as diferenças entre os tipos de locais para disposição de resíduos sólidos urbanos, 34\% alegaram não saber e $9 \%$ apresentaram algum tipo de dúvida.

Mesmo os resíduos domésticos sendo descartados em aterros sanitários, os quais são os locais previamente preparados e adequados para tal, quando bem monitorados e com uma excelente infra-estrutura, convivemos com processos que causam alguns impactos ambientais, especialmente sobre as águas de superfície e as águas subterrâneas.

Os entrevistados foram questionados sobre os prejuízos ao meio ambiente causados pelos aterros sanitários, onde, $51 \%$ das pessoas entrevistadas afirmaram que os aterros não são prejudiciais e $49 \%$ restantes afirmam que os aterros são prejudiciais quanto a questões ambientais.

Segundo Naime (2011) o lixo doméstico contém pilhas, baterias e lâmpadas fluorescentes, que é caracterizado como lixo domiciliar especial de classe I. Segundo a NBR 10.004 da Associação Brasileira de Normas Técnicas (ABNT) os resíduos estão classificados de acordo com sua periculosidade, sendo que o lixo domiciliar especial pertencente a classe de resíduos I ou perigosos os quais são aqueles que em função de suas características intrínsecas de inflamabilidade, corrosividade, reatividade, toxicidade ou patogenicidade, apresentam riscos à saúde pública por meio do aumento da mortalidade ou da morbidade, ou ainda provocam efeitos adversos ao meio ambiente quando manuseados ou dispostos de forma inadequada.

Aproximadamente $82 \%$ da população entrevistada no município de Frederico Westphalen possuem informação da presença de componentes tóxicos nos resíduos domésticos, $7 \%$ relataram não possuir informação e $11 \%$ restantes manifestaram duvida.

Em contrapartida, a opinião dos questionados se mostrou favorável quanto à disposição de materiais como, lâmpadas fluorescentes, medicamentos vencidos, pilhas e demais resíduos domésticos nesses aterros. Das 100 pessoas questionadas apenas $13 \%$ afirmaram que este tipo de lixo doméstico poderia ser depositado em aterros sanitários, os $87 \%$ restantes afirmaram que esses resíduos não poderiam ser depositados em aterros devido à alta taxa de elementos tóxicos e poluentes.

Segundo o Artigo 1o da Resolução n.ㅇ 001/86 do Conselho Nacional do Meio Ambiente (CONAMA), Impacto Ambiental é "qualquer alteração das propriedades físicas, químicas, biológicas do meio ambiente, causada por qualquer forma de matéria ou energia resultante das atividades humanas que afetem diretamente ou indiretamente: a saúde, a segurança, e o bem estar da população; as atividades sociais e econômicas; a biota; as condições estéticas e sanitárias ambientais".

O descarte incorreto dos resíduos domésticos acarreta impactos ambientais e problemas relacionados à saúde, $71 \%$ dos entrevistados afirmam ter conhecido sobre esta problemática, 19\% não tem conhecimento e $10 \%$ não souberam relatar.

$\mathrm{Na}$ figura 11, constam os dados referentes ao que deveria ser feito com os resíduos domésticos na opinião da população entrevistada em Frederico Westphalen, 71\% dos entrevistados dizem que o lixo deveria ser separado e reciclado, $14 \%$ dizem que devem ser dados destinos corretos a esses materiais, $4 \%$ modificam este pressuposto dizendo que este material deve ser apenas depositado em aterros e $11 \%$ restantes não tinham conhecimento sobre 0 assunto, conforme pode ser visualizado na figura 6 . 


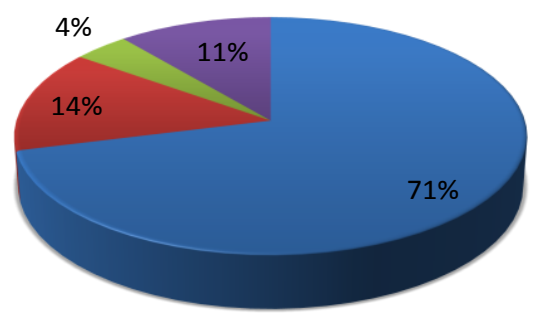

\author{
๑ Separação/Reciclagem \\ Destino Correto \\ $\square$ Aterros \\ Não sabem
}

Figura 6. Posição da população perante a destinação que deveria ser dada aos resíduos domésticos.

Ribeiro (2007) e Silva (2012) discutem a problemática ocasionada ao meio ambiente referente ao uso exacerbado e desnecessário de sacolas plásticas, há qual é derivada do petróleo, cuja queima pode ser uma das causas responsáveis do aquecimento global. O descarte indevido deste resíduo traz prejuízos diversos ao meio ambiente e podem ser vivíveis em todos os lugares. Muitas sacolas plásticas acabam em bueiros nas cidades, agravando o problema das enchentes, pois impedem a drenagem das águas das chuvas, retardam a decomposição de materiais biodegradáveis e quando jogados no mar contaminam os peixes.

Perguntou-se então sobre a posição do entrevistado referente às medidas a serem tomadas tendo como exemplo a aquisição de sacolas plásticas no comércio em geral na cidade de Frederico Westphalen. Dos entrevistados, 89\% responderam estar plenamente a favor dessas novas medidas e que elas até poderiam ser substituídas por métodos mais conscientes de consumo, como o uso de "sacolas ecológicas", e 11\% posicionaram-se contra esses novos métodos. Também buscou-se saber se o consumidor se sentiria motivado e influenciado ao uso de sacolas ecológicas se o comércio oferece-se benefícios como descontos ou promoções aos cidadãos que adotassem esses métodos de consumo consciente, tendo como resultado, $81 \%$ afirmaram que se sentiriam influenciados ao uso de sacolas ecológicas, outros $11 \%$ propunham que esta atitude deveria partir de cada indivíduo, por conscientização própria e $2 \%$ restantes, não souberam opinar.

Quando questionadas se já haviam presenciado ou participado de alguma campanha de conscientização sobre o destino que deve ser dado á este tipo de material, $51 \%$ das pessoas lembraram ter visto ou presenciado de alguma maneira campanhas de conscientização e $49 \%$ restantes alegaram que nunca tiveram nenhum tipo de informação ou instrução, nem presenciado nenhum tipo de campanha referente a este assunto. 


\section{CONCLUSÃO}

Após a realização desta pesquisa, com intuito de analisar e avaliar o conhecimento que a população frederiquense possui sobre os problemas ambientais ocasionados pelo uso e descarte incorreto dos resíduos domésticos pode-se observar que grande parte da população possui conhecimento sobre o tema. Porém percebe-se a ineficiência no que diz respeito à coleta e as formas de disposição dos resíduos, segundo a opinião dos moradores.

\section{REFERÊNCIAS}

ABRELPE - Associação Brasileira de Empresas de Limpeza Pública e Resíduos Especiais. Panorama de Resíduos Sólidos no Brasil - 2011. São Paulo: Abrelpe, 2011.

BRASIL. Resolução CONAMA $\mathbf{N}^{\circ} 001$, de 23 de janeiro de 1986. Disponível em: <http://www.mma.gov.br/port/conama/res/res86/res0186.html>. Acesso em: 25 de maio 2012.

BRASIL. Resolução CONAMA N005, de 05 de agosto de 1993. Disponível em: <http://www.mma.gov.br/port/conama/res/res93/res0593.html>. Acesso em: 20 abr. 2012.

GRANZIERA, M. L. M. Direito ambiental. São Paulo: Atlas, 2009.

IBGE - Instituto Brasileiro de Geografia e Estatística. Disponível em: <http://www.ibge.gov.br>. Acesso em: 18 maio de 2012.

IPT - INSTITUTO DE PESQUISAS TECNOLÓGICAS DO ESTADO DE SÃO PAULO. Lixo Municipal: manual de gerenciamento integrado. São Paulo: IPT/CEMPRE. 1995. 278p. Disponível em: <http://www.rc.unesp.br/igce/aplicada/ead/ residuos/res12.html> Acesso em: 01 maio 2012.

NAIME, R. Classificação de resíduos, segundo a NBR 10.004. Ecodebate, ago. 2011. Disponível em: <http://www.ecodebate.com.br/2011/08/01/classificacao-de-residuos-segundo-a-nbr-10-004-artigo-de-robertonaime/>. Acesso em: 25 maio 2012.

OLIVEIRA, A. C. M. A. A responsabilidade na destinação dos resíduos sólidos domésticos. Disponível em: <http://www.pucrs.br/edipucrs/XSalaolC/Ciencias_Sociai

s_Aplicadas/Direito/70793-ANA_CHRISTINA_MAJOLO_ALVES_DE_OLIVEIRA.p

df>. Acesso em: 05 abr. 2012.

PIMENTA, Selma Garrido, GHEDIN, Evandro e FRANCO, Amélia Santoro (Org.). Pesquisa em educação: alternativas investigativas com objetos complexos. São Paulo: Loyola, 2006. 198 p.

RAMOS, L. F. P. et al. Educação em saúde, lixo doméstico e sociedade. Disponível em: <http://www.ambienteaugm.ufscar.br/uploads/A3-101.pdf>. Acesso em: 05 abril 2012.

REIS, B. L.; FADIGAS, A. F. A. E.; CARVALHO, E.C. Energia, Recursos Naturais e a Prática do Desenvolvimento Sustentável. 2. ed. São Paulo: Manole, 2012. Cap. 4, p. 135-136.

RIBEIRO, J. A. Crescimento Populacional Versus Acúmulo de Resíduos Sólidos: a percepção econômico-ambiental dos moradores de Porto de Galinhas. 2006. 93 p. Monografia (Bacharelado em Ciências Econômicas) - Universidade Federal rural de Pernambuco, Recife. 
RIBEIRO, C. Empreendedores vêem a substituição do produto uma boa oportunidade de negócios, dez. 2007. Disponível em: <http://www.responsabilidadesocial.com/article/article_view.php?id=549>. Acesso em: 01 jun. 2012.

SILVA, D. Quais os impactos ambientais das sacolas plásticas? Disponível em: <http://www.ressoar.org.br/dicas_reciclagem_sacolas_oxiobiodegradaveis_impactos.asp> Acesso em: 19 maio 2012.

SNIS - Sistema Nacional de Informações sobre Saneamento. Programa de modernização do setor de saneamento: diagnóstico da gestão e manejo de resíduos sólidos urbanos - 2008. Brasília: MCidades, SNSA, 2010. 